Article

\title{
Deriving High Spatial-Resolution Coastal Topography From Sub-meter Satellite Stereo Imagery
}

\author{
Luís Pedro Almeida ${ }^{1,2, *} \mathbb{\infty}$, Rafael Almar ${ }^{3}\left(\mathbb{D}\right.$, Erwin W. J. Bergsma ${ }^{2}{ }^{(D}$, Etienne Berthier ${ }^{4}(\mathbb{D}$, \\ Paulo Baptista ${ }^{5}$, Erwan Garel ${ }^{6}\left(\mathbb{D}\right.$, Olusegun A. Dada ${ }^{7}$ and Bruna Alves ${ }^{3}$ \\ 1 Instituto de Oceanografia, Universidade Federal do Rio Grande (IO-FURG), 96203-000 Rio Grande, Brazil \\ 2 Centre National d'Études Spatiales (CNES-LEGOS), 31400, Toulouse, France; \\ erwin.bergsma@legos.obs-mip.fr \\ 3 Institut de recherche pour le développement (IRD-LEGOS), 31400 Toulouse, France; \\ rafael.almar@legos.obs-mip.fr (R.A.); oc.bruna@gmail.com (B.A.) \\ 4 Centre National de la Recherche Scientifique (CNRS-LEGOS), 31400 Toulouse, France; \\ etienne.berthier@legos.obs-mip.fr \\ 5 Departamento de Geociências, Centro de Estudos do Ambiente e do Mar (CESAM), Universidade de Aveiro, \\ Campus de Santiago, 3810-193 Aveiro, Portugal; renato.baganha@ua.pt \\ 6 Centre for Marine and Environmental Research (CIMA), University of Algarve, 8005-139 Faro, Portugal; \\ egarel@ualg.pt \\ 7 Department of Marine Science and Technology, Federal University of Technology, 340252 Akure, Nigeria; \\ oadada@futa.edu.ng \\ * Correspondence: melolp@gmail.com
}

Received: 15 January 2019; Accepted: 6 March 2019; Published: 12 March 2019

\begin{abstract}
High spatial resolution coastal Digital Elevation Models (DEMs) are crucial to assess coastal vulnerability and hazards such as beach erosion, sedimentation, or inundation due to storm surges and sea level rise. This paper explores the possibility to use high spatial-resolution Pleiades (pixel size $=0.7 \mathrm{~m}$ ) stereoscopic satellite imagery to retrieve a DEM on sandy coastline. A 40-km coastal stretch in the Southwest of France was selected as a pilot-site to compare topographic measurements obtained from Pleiades satellite imagery, Real Time Kinematic GPS (RTK-GPS) and airborne Light Detection and Ranging System (LiDAR). The derived 2-m Pleiades DEM shows an overall good agreement with concurrent methods (RTK-GPS and LiDAR; correlation coefficient of 0.9), with a vertical Root Mean Squared Error (RMS error) that ranges from 0.35 to $0.48 \mathrm{~m}$, after absolute coregistration to the LiDAR dataset. The largest errors (RMS error $>0.5 \mathrm{~m}$ ) occurred in the steep dune faces, particularly at shadowed areas. This work shows that DEMs derived from sub-meter satellite imagery capture local morphological features (e.g., berm or dune shape) on a sandy beach, over a large spatial domain.
\end{abstract}

Keywords: Pleiades; photogrammetry; LiDAR; RTK-GPS; beach topography

\section{Introduction}

Accurate topographic data are frequently needed for the assessment of rapid morphological changes and for the implementation of models that can predict coastal evolution. High spatial resolution coastal Digital Elevation Models (DEMs-defined here as the representation of the terrain surface elevations at regularly spaced intervals) are used to support vulnerability and risk assessment of a range of coastal hazards, such as beach erosion and sedimentation, storm surges, inundation, and sea level rise [1]. For such studies, the availability of a topographic dataset is fundamental, in particular for coastal systems characterized by a complex, rapidly evolving morphology. 
Among topographic survey methods of suitable quality, those based on Global Navigation Satellite Systems (GPS), such as Real Time Kinematic GPS (RTK-GPS), have been used extensively to map and monitor coastal morphology [2]. Beach topographic surveys using RTK-GPS method can be performed either by walking and carrying a GPS receiver, or driving a mobile unit (e.g., quad bike). In both cases, the vertical precision is approximately 0.05 to $0.1 \mathrm{~m}$, depending on the terrain relief [2]. This method typically requires an intense human effort, which normally is optimized by reducing the number of measurements to a limited number of cross-shore sections of the beach. Nevertheless, this limited spatial coverage results in an incomplete representation of topographic spatial patterns and evolving features, especially in the case of complex topographies such as steep and unconsolidated slopes. In such cases, interpolation methods are typically required, introducing additional uncertainty into the DEM [3].

Remote sensing techniques, such as airborne LiDAR (Light Detection and Ranging) and Unmanned Aerial Vehicle (UAV), emerge in this context as a solution to overcome the limited spatial coverage of the RTK-GPS method [4-9]. The use of airborne LiDAR to measure geomorphological changes in coastal areas is relatively new. This instrumentation acquires millions of $x, y, z$ points per hour, with a horizontal spacing of typically 1 to $3 \mathrm{~m}$. This high spatial resolution, together with the capacity to survey over large areas (from $10^{1}$ to $10^{5} \mathrm{~m}$ ), allows overcoming traditional survey limitations found with RTK-GPS [2]. The vertical accuracy of LiDAR ranges from $0.05 \mathrm{~m}$ to $0.15 \mathrm{~m}$ [5], which is in the same order as RTK-GPS and appropriate for studying beach morphology. Nonetheless, LiDAR-based DEMs are costly [5,6], which limits the frequent (e.g., monthly or-post-storm) acquisition of large-scale topographic data adequate for the evaluation of coastal changes.

Airborne optical remote sensing and 3D-mapping have been serving the needs of regional-scale low-altitude imaging and geospatial information [10]. The enhanced usability of recent UAV equipment with onboard accurate positioning, such as off-the-shelf drones, has resulted in a large change in their practical application. The RTK-GPS positioning of the camera, combined with the large number of overlapping images, makes any additional ground surveys trivial. Moreover, the high degree of automation of UAVs and the absolute vertical precision, of approximately $0.2 \mathrm{~m}$, achieved by the DEMs suggests possible uses in the fields of natural hazards, disaster response, and high-resolution terrain analysis [6]. Despite these advantages, a few disadvantages still remain such as the cost of the photogrammetric software and computer power that can be relatively high [7], the difficulty in removing dense vegetation to obtain bare earth elevation estimates [11], the need for electric batteries for longer flight duration, or the usage limitations related to weather conditions [12].

Sub-meter satellite imagery can potentially provide an alternative to these field-based techniques in order to collect high spatial resolution topographic data over large areas. The first civil satellite constellation that acquired stereoscopic imagery and applied DEM reconstruction over large areas was the French SPOT mission (Satellite Pour l'Observation de la Terre) in 1986 [12]. Since then, several very high spatial resolution satellites with stereo capabilities were launched in response to an increased demand [13]. Among them, the Pleiades constellation (built by the French Space Agency (CNES), commercialized by AIRBUS Defence \& Space), consists of two high spatial resolution optical spacecrafts: Pleiades $-1 \mathrm{~A}$ and $-1 \mathrm{~B}$. Both satellites fly over the same near-polar sun-synchronous orbits at an altitude of $694 \mathrm{~km}$ with a $180^{\circ}$ phase and descending node. The optical sensors of these satellites have the capability to obtain images with sub-meter image resolution $(0.7 \mathrm{~m}$ pixel size, resampled to $0.5 \mathrm{~m}$ ) over a maximum area of $350 \mathrm{~km} \times 20 \mathrm{~km}$ (swath width of $20 \mathrm{~km}$ at nadir). An important aspect of Pleiades is the capacity to revisit any location in the world within 1 day, which is of great interest to monitor rapidly changing processes (e.g., coastal erosion due to storm events). Recent studies based on Pleiades-1A stereo-imagery include snow height mapping in mountainous areas [14], large landmass deformations due to earthquakes [15], surface reconstruction after landslides [16], and glacier topography $[17,18]$.

The aim of the present work is to explore the use of Pleiades satellite stereo-imagery to develop a high resolution DEM of a 40-km-long sandy coastal section. The satellite-derived DEM is compared 
to RTK-GPS cross-shore profiles and an airborne LiDAR-derived DEM. The differences between the concurrent methods are quantified and the precision and accuracy of Pleiades-DEM analysed.

\section{Study Site and Data Acquisition}

A 40-km stretch of sandy coast in the South West of France was selected as the study site for the present work (Figure 1). This section of the Aquitanian coast presents a relatively low shoreface bordered by aeolian dunes with an average crest elevation of about $15 \mathrm{~m}$ [19-21]. The sediment consists of fine to medium quartz, with mean grain sizes ranging from 200 to $400 \mu \mathrm{m}$ [21]. This section of the coast is characterized by a macro-tidal regime, with an average tidal range of $3.2 \mathrm{~m}$ that can reach $5 \mathrm{~m}$ during spring tides [22]. The coast is exposed to high energy North Atlantic swells travelling mainly from the W-NW sector [23].

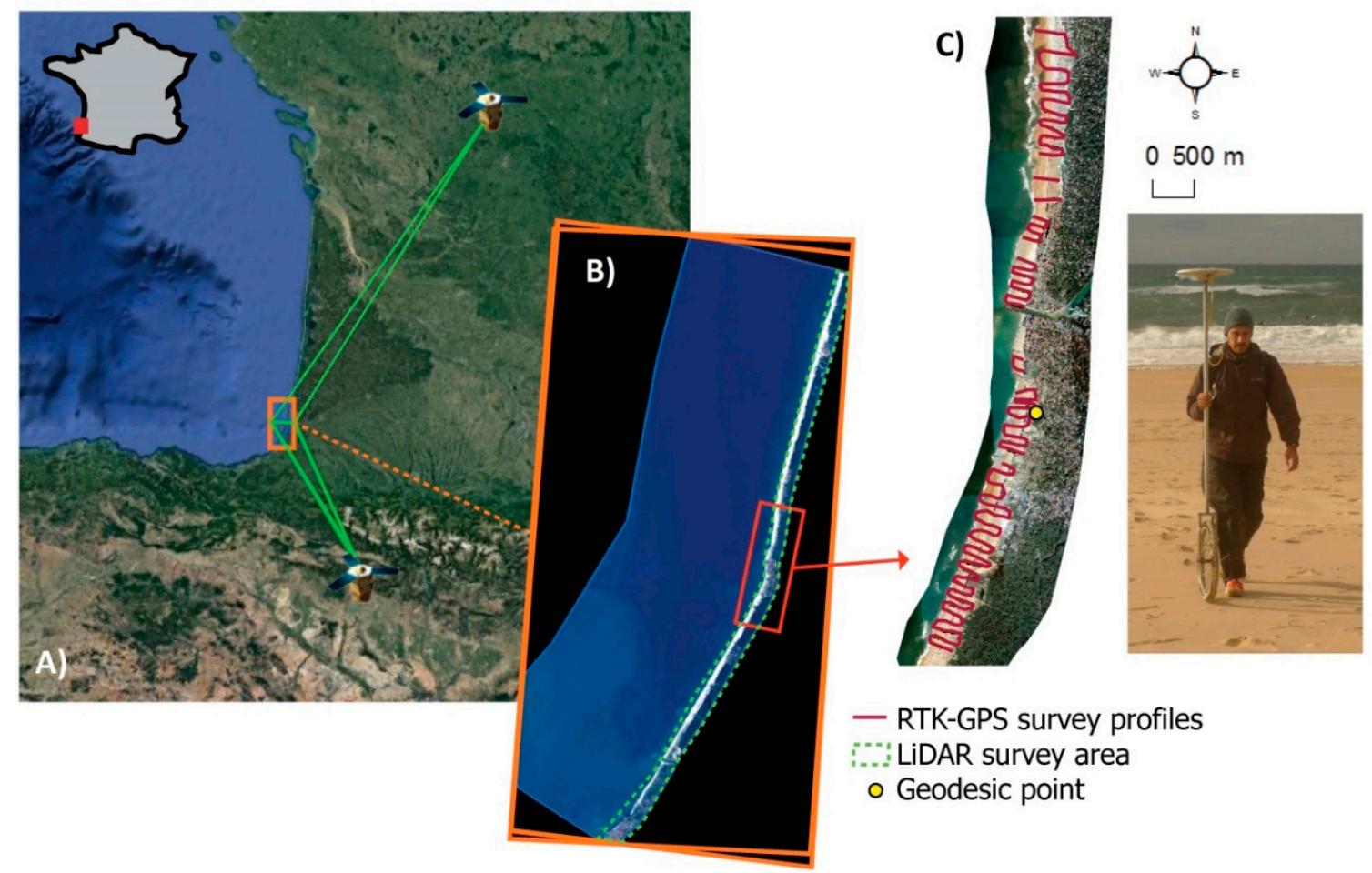

Figure 1. Satellite image of the West of France (source: Google Earth Pro 2018) showing the location where Pleiades stereo-pair was obtained (orange rectangle located in the Southwest of France) on the $14^{\text {th }}$ of November 2017 (A). Zoom in of the Pleiades mosaic showing the area where the airborne-LiDAR topographic survey was performed (polygon with dashed green outline) and the region where RTK-GPS topographic measurements were undertaken (B). Panel (C) shows the RTK-GPS survey lines (red) and photograph of the surveyor with the GPS rover unit.

The Pleiades-HR 1A (hereinafter referred to as PL1A) stereo-pair was acquired on 14 November 2017 over a predefined area (orange box in Figure 1). The optical stereo-pair was obtained between 11:15 a.m. and 11:16 a.m. with a 40-s time-lag. The satellite orbits at $694 \mathrm{~km}$ altitude (base to height ratio of 0.36) and follows a descending orbit trajectory (North-South) in WGS84 decimal coordinates. A topographic DEM and ortho-image, covering the entire area of interest, was subsequently produced using NASA's AMES Stereo Pipeline [24].

In-situ RTK-GPS beach topographic measurements were used as ground-truth for inter-comparison with the Pleiades and LiDAR DEMs. The RTK-GPS survey was performed in the central section of the area of interest (coastal region of Capbreton) between the $7^{\text {th }}$ and $9^{\text {th }}$ of November 2017 (Figure 1). The average tidal range during the beach surveys was $3.4 \mathrm{~m}$ with a moderate wave climate (wave height under $3 \mathrm{~m}$ ). Beach profiles were surveyed in continuous mode (waypoint every 1 second using a 
position dilution of precision-PDOD-mask of 3) from the waterline to the back of the frontal dune ridge along discrete cross-shore profiles spaced by approximately $250 \mathrm{~m}$ (Figure 1). Note that due to radio transmission shadowing (resulting in no real time correction) or ground obstacles (e.g., fences, walls, etc.), the survey coverage presents some spatial irregularities (Figure 1). In addition to the RTK-GPS dataset, a high resolution airborne-LiDAR topographic survey and orthophoto map (aerial imagery was orthorectified with the LiDAR observations) of the entire SW coast of France (performed by the Institut National de L'Information Geographic et Forestiere-IGN; in cooperation with the Bureau de Recherches Géologiques et Minières_BRGM) were acquired in October 2017.

\section{Methods}

\subsection{Pleiades Stereo-imagery Acquisition and DEM Generation}

In the present experiment, stereo images were acquired when the angles between the line-of-sight of the satellite camera and the horizontal plane of the ground were $72^{\circ}$ and $76^{\circ}$, for the first and second images respectively. The ground projection of the Pleiades position during the stereo-pair collection was 218 and $174 \mathrm{~km}$ from the coast respectively. Pleiades was overlooking the coastal area of interest from the sea side. This satellite setup indicates that both images were collected close to nadir angle $\left(90^{\circ}\right.$ from the ground), with an azimuth of $19^{\circ}$ for the first and $-8^{\circ}$ for the second image, resulting in an azimuth angle difference of $27^{\circ}$ between the two images.

The Pleiades panchromatic band of the stereo pair was processed using the Ames Stereo Pipeline, ASP [24] to generate a DEM and ortho-images at 2 and $0.5 \mathrm{~m}$ resolution, respectively. The ASP uses the rational polynomial coefficient (RPC) camera model format for the DEM generation. The RPC model is provided in the imagery metadata (by AIRBUS) and gives a relationship between the image coordinates and the ground coordinates. No ground control points were initially used in the DEM generation. The planimetric coordinates were referenced to the WGS84 UTM 30N coordinate system and the heights were computed above the WGS84 ellipsoid. The Pleiades DEM and ortho-images were a posteriori coregistered by applying a first order polynomial transformation defined by 37 concomitant points manually identified in the Pleiades-ortho and DEM and in the IGN/BRGM orthophoto map (used as the reference). This process was performed with QGIS software and Georeferencer GDAL plugin, with an average planimetric error of $0.5 \mathrm{~m}$. To convert Pleiades altimetric data from WGS1984 to the French NGF-IGN vertical datum, the Pleiades elevations were corrected from the average difference with the LiDAR elevations (Pleiades elevations $12.2 \mathrm{~m}$ higher) determined at the same point locations and then used for the planimetric correction.

\subsection{RTK-DGPS Topographic Survey}

The planimetric coordinates of the RTK-DGPS topographic survey were referenced to the World Geodetic System (WGS84) while the vertical datum was referenced to NGF-IGN 1969 datum. A GPS base station was installed in a local geodesic point (located near Capbreton - Figure 1) and provided, in real time, the corrections to the mobile GPS unit via radio-transmission. After the survey, the planimetric coordinates were converted to the same coordinate system as the Pleiades products (WGS 84 UTM 30N), and spikes in the data (erroneous measurements) were eliminated. The processed topographic measurements were subsequently divided into individual profiles and interpolated in the cross-shore direction with $2 \mathrm{~m}$ spacing (to match the resolution of the Pleiades DEM). Comparisons between RTK-GPS ground-truth and remotely sensed Pleiades and LiDAR DEMs were performed by extracting values from the DEMs at each profile location (using all RTK-GPS point measurements). This task was performed using QGIS software (Lyon version) and the function "sample raster maps at point location" from GRASS-GIS toolbox. The data comparisons included the calculation of statistical parameters such as the correlation coefficient (CC), root mean squared (RMS) error, and bias (BIAS) using all RTK-GPS topographic observations. 


\subsection{Airborne LiDAR 3D Topographic Survey}

As part of a regional coastal monitoring program, the Aquitaine coastal zone is surveyed every year with airborne LiDAR by the IGN in cooperation with the BRGM. In the present work, the LiDAR topographic survey of the Aquitaine coast performed between 4 and 7 of October 2017 was used for comparison with the RTK-GPS and Pleiades observations. Note that the LiDAR survey was executed approximately a month before the field campaign and Pleiades acquisition. The airborne-LiDAR survey was performed with the Leica ALS70-HP LiDAR, mounted on an aircraft, and acquiring topographic information with a density of 8 points per square meter. The planimetric coordinates of the LiDAR point-cloud were referenced to the Lambert 93 coordinate system, with a precision of $30 \mathrm{~cm}$, and terrain topography referenced to the NGF-IGN 1969 datum, with an accuracy of $15 \mathrm{~cm}$ (information provided by the LiDAR survey metadata). Simultaneously with the LiDAR acquisition, high resolution $(10 \mathrm{~cm}$ ) aerial orthophotography was obtained with an 8-head IGN V2 (focal length of $135 \mathrm{~mm}$ ) camera. The position and orientation of the images were obtained from the GPS and inertial sensors embedded in the aircraft. Two products were obtained from this flight: a DEM of the study area, with a spatial resolution of $1 \mathrm{~m}$, and an orthophoto map with $10 \mathrm{~cm}$ resolution. For comparison with the other datasets, the coordinate systems of these LiDAR products were converted to WGS 84 UTM $30 \mathrm{~N}$.

\section{Results}

\subsection{Comparison between RTK-GPS, Pleiades and LiDAR Topography}

Figure 2 shows the vertical difference between the three concurrent survey methods over 4138 points (i.e., the number of data points measured during the RTK-GPS survey). The differences between remote sensing methods (Pleiades and LiDAR) and RTK-GPS are normally distributed, with mean differences (BIAS) of $0.01 \mathrm{~m}$ and $0.03 \mathrm{~m}$, and RMS errors of $0.35 \mathrm{~m}$ and $0.37 \mathrm{~m}$ for Pleiades and LiDAR respectively (both Pleiades and LiDAR elevations are slightly higher than the RTK measurements). The observed slight mean difference between the RTK-GPS and remote sensing methods are within the accuracy of the RTK-GPS, thus indicating that the different methods have similar accuracy. It is important to note that even though the LiDAR data have a larger RMS error than the Pleiades one, the error distribution is narrower and skewed for negative values. The 1:1 scatter-comparison of the surveys shown in Figure 2 indicates that the remotely-sensed beach topography is highly correlated with the RTK-GPS observations (slope $=1.01$ and CC $=0.99$ for both Pleiades and LiDAR). It is also observed that the correlation with Pleiades values does not vary with elevation (extending from the back of the dune to the top of the swash zone) while for LiDAR some scattering is observed in the lower part of the beach (beach face).

A close inspection of the datasets indicates the scatter (observed in the beach face) between RTK-GPS and LiDAR topography was due to morphological changes (berm erosion-Figure 3) over the beach profile that occurred between the two surveys. During this period of the year (winter season), this coastal area is under energetic waves and significant morphological changes $(>1 \mathrm{~m})$ in the beach and dune face are likely to occur [23]. Considering that the RTK-GPS survey and Pleiades image acquisition were days apart, small morphological changes likely occurred in the beach face, resulting in minor differences between the two datasets (Figure 3). 

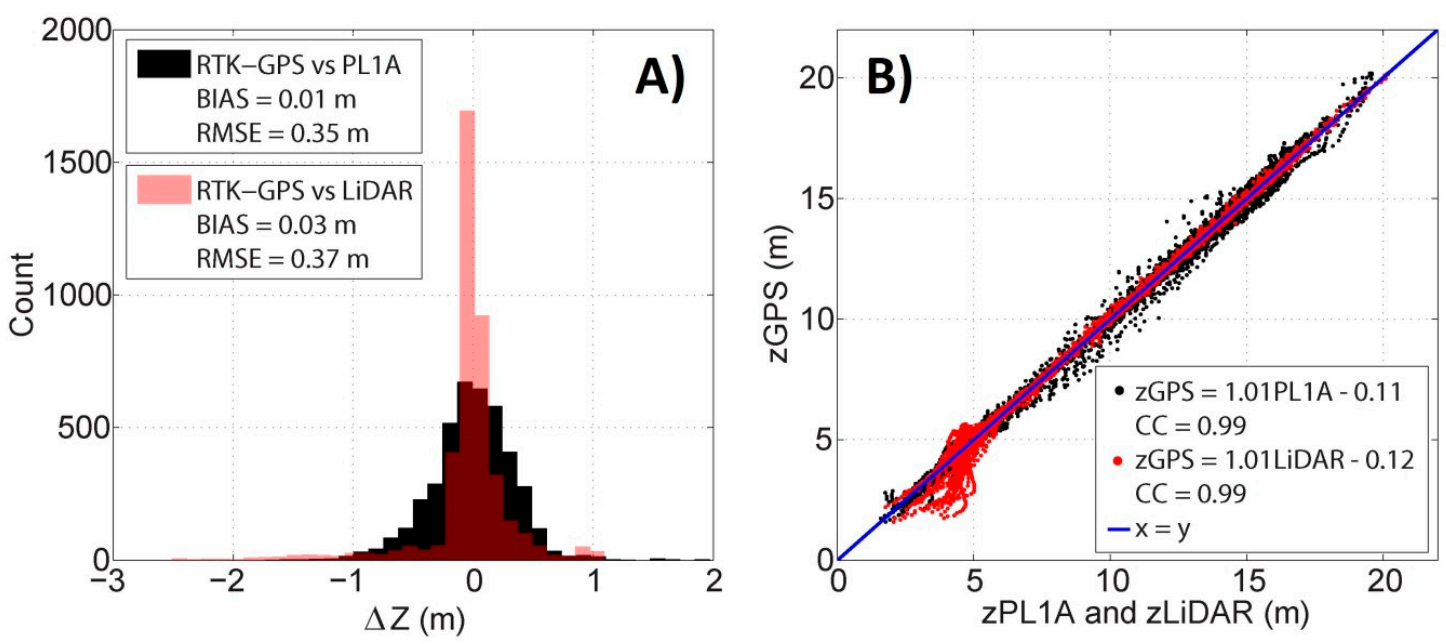

Figure 2. Pleiades (PL1A) and LiDAR survey accuracy assessed by comparison to concurrent on-ground RTK-GPS survey; histogram of the differences between elevations measured by RTK-GPS and remote sensing methods; (A); scatter plot of RTK-GPS elevations vs remotely sensed elevations (B).
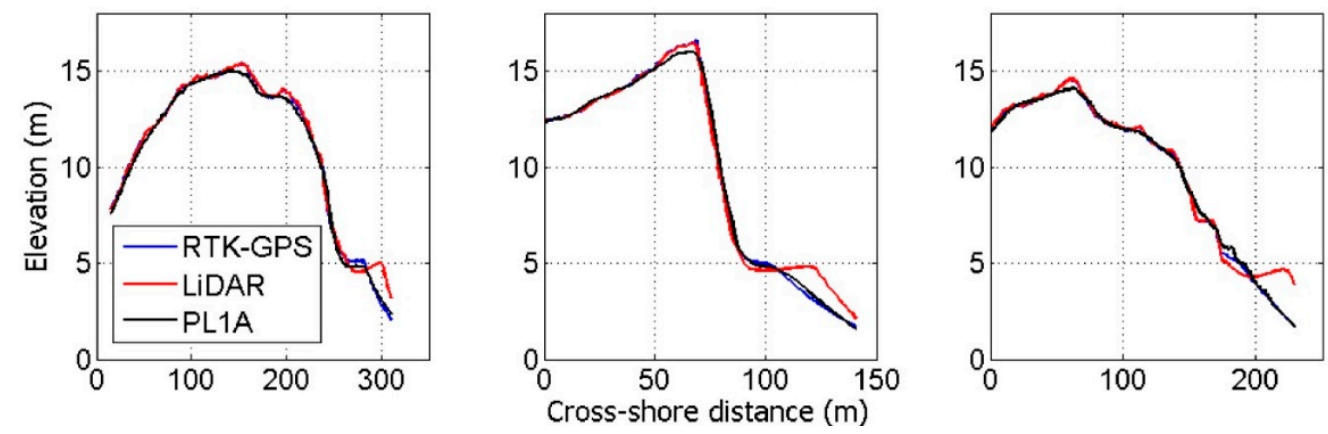

Figure 3. Three beach profiles showing the comparison between RTK-GPS, Pleiades (PL1A) and LiDAR, showing the berm erosion that occurred between the LiDAR survey and RTK-GPS and Pleiades.

\subsection{D Beach Topography Comparisons}

Figure 4 shows the two DEMs produced using Pleiades stereo imagery and LiDAR data, together with the difference between the two DEMs (Pleiades DEM minus LiDAR DEM). The northern part of the study area (North of Capbreton-Figure 4) presents higher dune fields than the South, and Pleiades DEM was able to capture this spatial variability with the same quality as the LiDAR. The difference between the two DEMs shows that over the full domain, $70 \%$ of the difference lies within $\pm 0.5 \mathrm{~m}$. Areas with positive elevation difference (i.e., Pleiades higher than LiDAR) are located between the frontal dune face and swash zone, while a negative difference was found more often at the back of the dune. A preliminary inspection of the alongshore error distribution allowed identifying larger differences at the dune face region between Capbreton and Labenne (Figure 4) in comparison to the rest of the domain. Within the section with these particular large differences, it was possible to identify the presence of shadows (for each transect, the length of the shadow was manually digitized from the orthophotomap) in the dune face that coincided with the areas where the largest errors were observed (Figure 5).

Specific ground characteristics, such as the slope and aspect [25,26], can have an indirect impact on the remotely-sensed DEM quality in regions with high relief, such as dunes. The presence of shadows in the dune face is determined by the steepness (slope) and orientation (aspect) of the topography in relation to the Sun light (for a given Sun altitude and azimuth). Optical remote sensing images from shadowed areas have low reflectance and texture, which alters the calculation of the disparity (which 
is later converted into elevation) of corresponding points in the stereo-pair and leads to less accurate elevations $[27,28]$.

In order to investigate the effect of the alongshore variability in the dune slope (front and back faces) and of the shadowed areas on the Pleiades DEM error, 266 cross-shore transects spaced $150 \mathrm{~m}$ apart were created. For each transect, the RMS error of the elevation difference (between Pleiades and LiDAR DEMs) over the dune face and back of the dune was computed. Figure 6 shows the RMS error variation along the $40 \mathrm{~km}$ of measured coastline together with the variations in the dune slope and shadow length in the dune face. The RMS error shows significant variations between transects, with values of similar magnitude on the dune face and back of the dune. The exception, as noted in Figure 4, is the coastal stretch between Capbreton and Labenne where a peak of RMS error $(>0.5 \mathrm{~m})$ is identified on the dune face. The alongshore location of this peak coincides with a relatively steep dune face region (large slope values) and the largest shadow regions (Figure 6). Steep dune face slopes were also present in the North section of the study area; however, the errors in this region were within the average, suggesting that the dune slope by itself cannot explain the largest errors observed. Shadowing at the dune face is more likely to represent a decisive quality factor of the produced DEM, considering the strong correlation between the RMS error and shadowing $(C C=0.77)$.
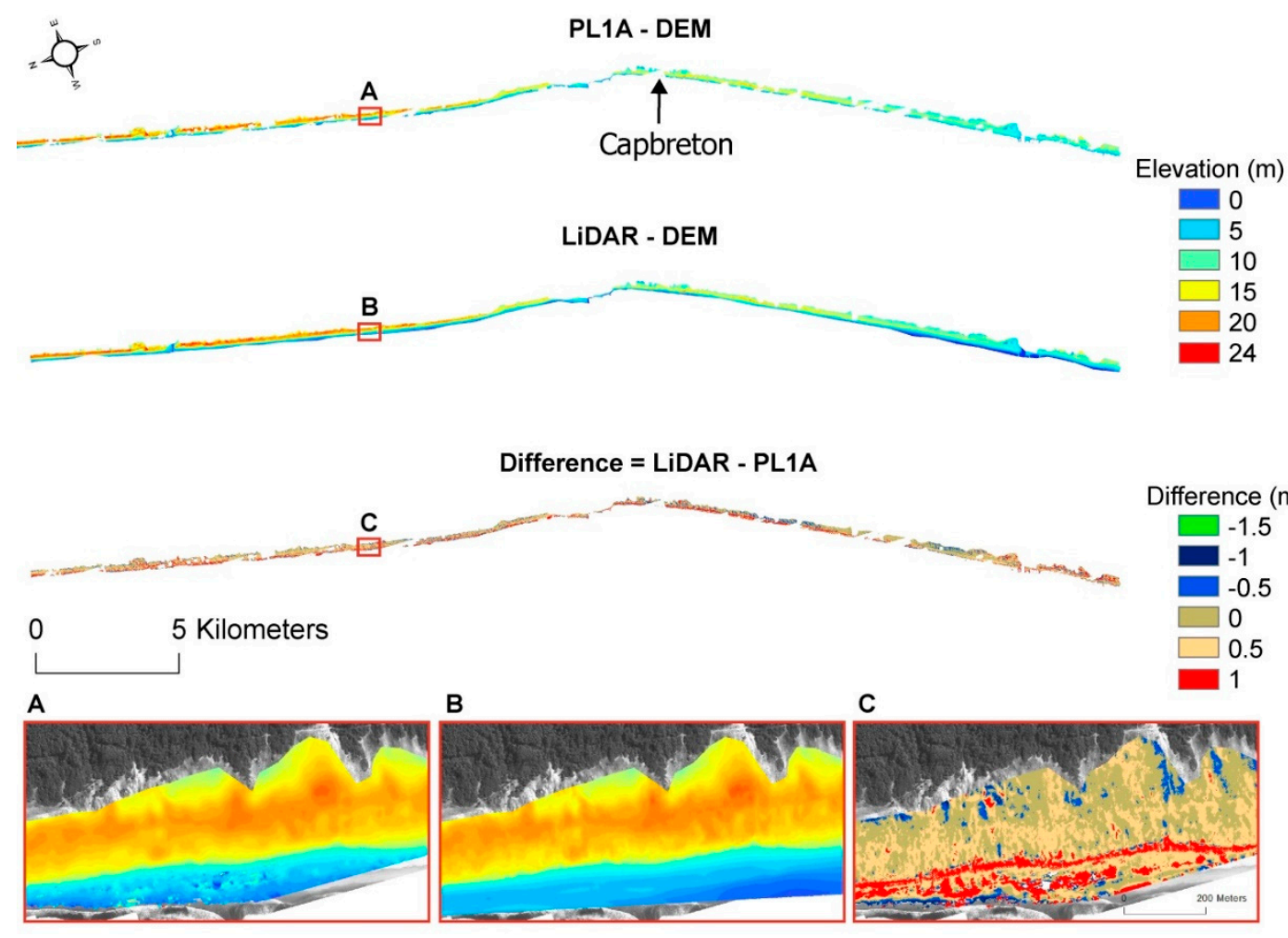

Figure 4. Results of the comparisons between the Pleiades (PL1A) and LiDAR DEMs. The lower panel presents three subsections of the study area showing the DEM produced with Pleiades (A), LiDAR (B) and the difference between the two $(C)$. Note that the maps of the DEMs were rotated $110^{\circ}$ in order to present them horizontally. 

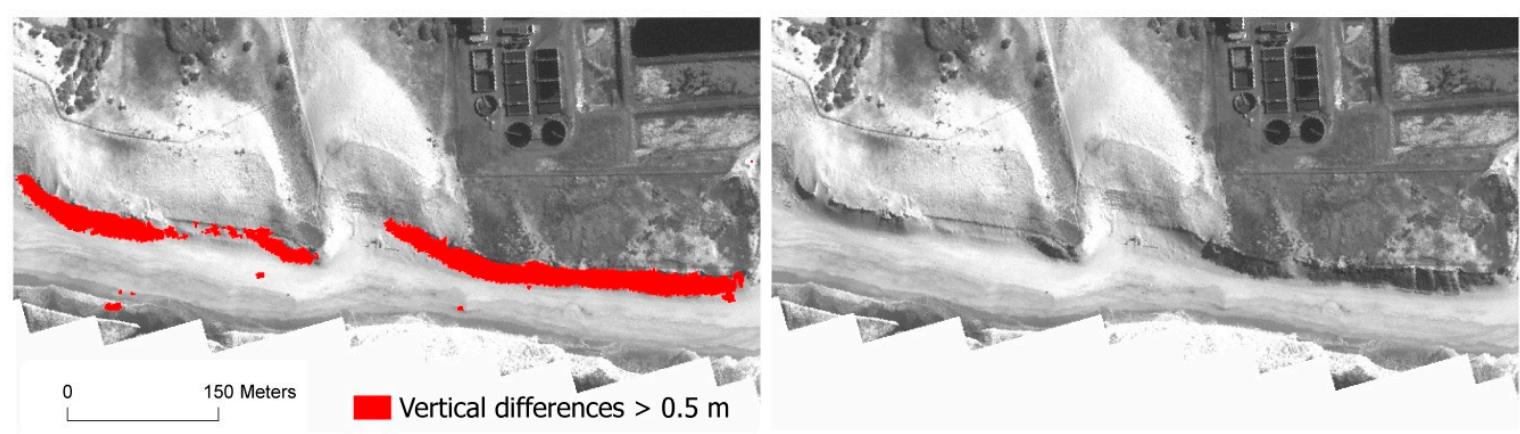

Figure 5. Example of the errors observed on the dune face, over the Pleiades orthophotomap; the presence of shadows on the dune face (right image) coincides with the area where the largest differences $(>0.5 \mathrm{~m}$ in red, left image) were observed (left image).
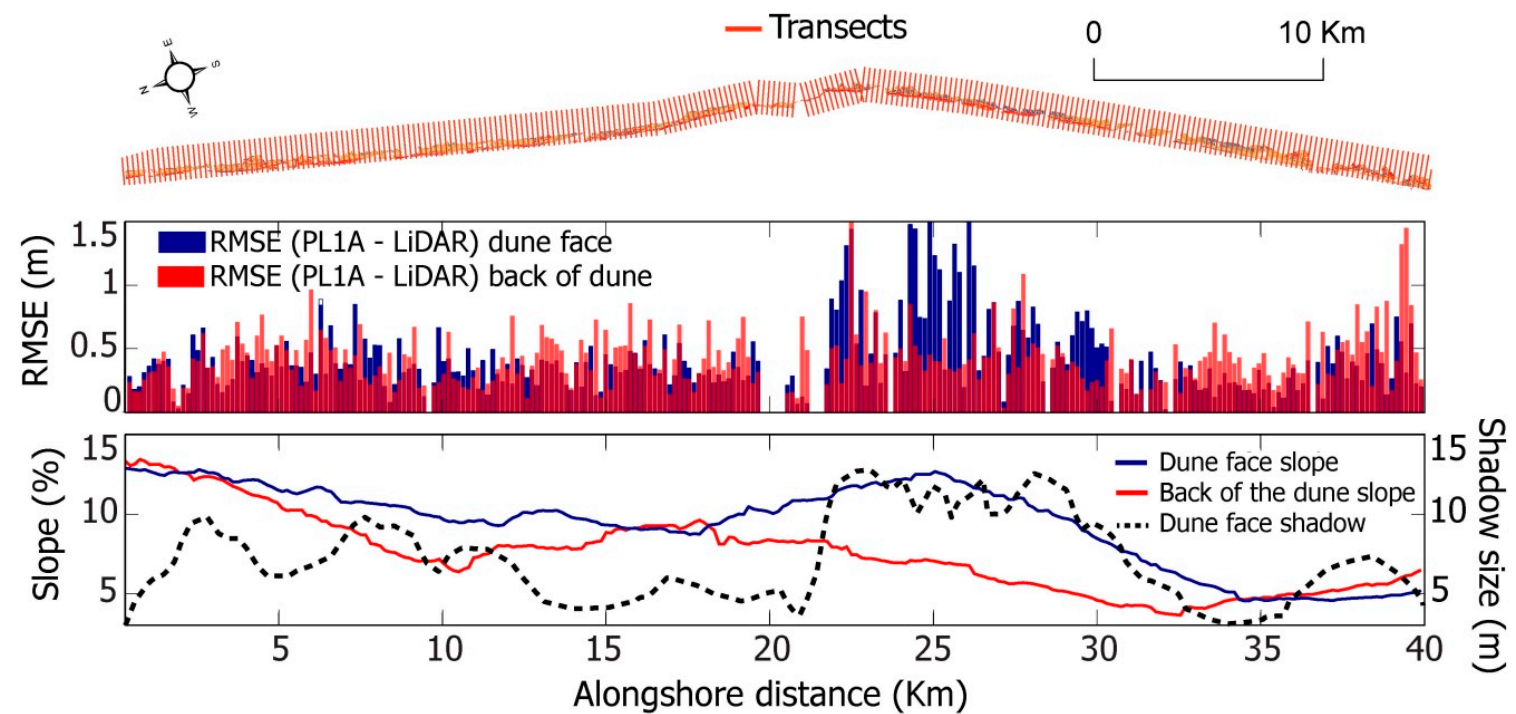

Figure 6. Results of the RMS error, slope and shadow calculations for the 266 cross-shore transects. The second panel (from the top) presents the RMS error of the difference between Pleiades (PL1A) and LiDAR topographic elevations, computed for the dune face and back of the dune; the bottom panel shows the dune face and back of the dune slope (bottom panel) and the shadow size (length of the shadow over each transect).

Figure 7 show the statistical evaluation of the comparison between the Pleiades and LiDAR elevations extracted over the 266 cross-shore transects (Figure 6). Data from the beach face, containing natural morphological changes (not related to the method), were removed from this statistical comparison. The error distribution indicates that differences between the LiDAR and Pleiades DEMs over the full domain are normally distributed with a mean difference of $-0.015 \mathrm{~m}$ and RMS error of $0.48 \mathrm{~m}$ (LiDAR DEM is slightly higher). The 1:1 comparison (Figure 7) shows that Pleiades and LiDAR beach topographies are highly correlated (slope $=1.01$ and $\mathrm{CC}=0.99$ ). 

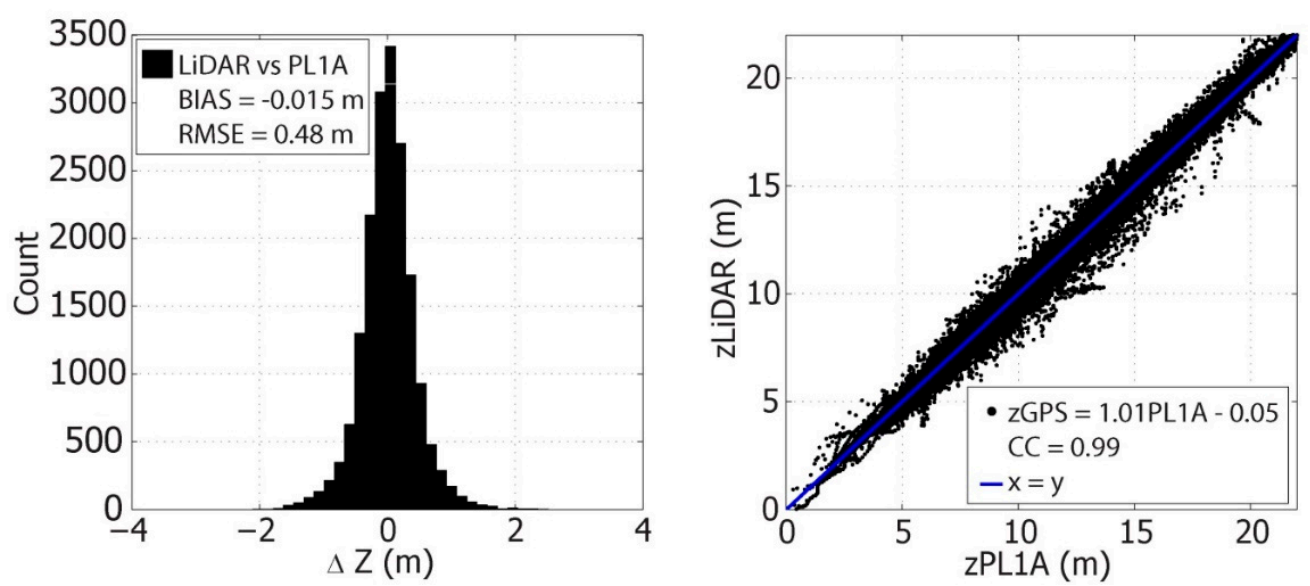

Figure 7. Pleiades (PL1A) topographic measurements accuracy assessed by comparison with LiDAR topographic measurements over points collected along 266 transects.

\section{Discussion}

The Use of Pleiades to Survey and Monitor Coastal Areas

The comparisons presented in Sections 4.1 and 4.2 indicate that Pleiades DEM reaches a vertical accuracy (BIAS) and precision (RMS error) similar to state-of-the-art survey methodologies used in coastal areas such as the RTK-GPS and LiDAR. Although in this study a comparison between Pleiades and UAVs stereo-topographic DEM was not presented, there are a few differences between these two methods that are important to take into consideration when deciding which of the methods to use. Both methods obtain the DEM based on photogrammetric techniques that estimate a 3D point-cloud of the ground surface using a large number of matching object and textural features automatically detected in the overlapping images. The low altitude and capacity to obtain images from many different view angles allows UAVs to obtain detailed 3D reconstruction of the ground surface with centimetric spatial resolution $[7,29]$. These characteristics represent an important advantage of the UAV technique when surveying highly complex coastal features (e.g., irregular rocky coastlines; [30]) or avoid the influence of sunlight exposure in the target features, such as the presence of shadows.

As it was observed in the present work, the presence of shadows can affect the quality of the DEM from stereo-satellite imagery (Figures 5 and 6). A similar problem was identified by [13] when validating the Pleiades tri-stereo digital surface model on an urban area. The fact that Pleiades, stereo and tri-stereo, only obtains images along a fixed trajectory, this limits the view angles of the ground surface (one backward looking, one forward looking, plus a third near-nadir image, in the tri-stereo configuration), making difficult an appropriate DEM estimation from features affected by shadows.

Despite this limitation, the present results show that Pleiades stereo imagery has the capability to capture local beach features such as berms or dunes crests and troughs over large domains, highlighting its incomparable advantage to any other existing methodology. These unique skills allow the Pleiades constellation to potentially overcome traditional survey challenges in coastal areas, such as the acquisition stereo-imagery measurements in large coastal segments within a short period of time (i.e., minutes). For traditional survey methods, this would mean a gigantic logistical challenge and expensive exercise. Furthermore, Pleiades' capacity to acquire imagery anywhere on the globe within 1 day is ideal for rapid response assessment of changes in the coastal zone (e.g., to assess morphological changes after storms).

A potential drawback of the Pleiades constellation is the on-demand availability, which is different from other observation missions like Landsat (NASA) or Sentinel (ESA) that acquire optical imagery on a regular basis without any previous request. In addition to this, another potential limitation of our processing flow is the dependence of ground control points to correct the vertical offset of the DEM and geometric inaccuracies of the raw data. This aspect limits the use of Pleiades DEM for applications 
where the absolute error in relation to a specific datum is required. Nevertheless, for cases where the offset to the local vertical datum is secondary, the inter-comparison between consecutive Pleiades DEMs is likely to result in errors within the precision of the method.

\section{Conclusions}

The beach topography of a 40-km-long sandy coastal stretch, located in the southwest of France, was surveyed by satellite Pleiades stereo-imagery. The computed DEM was compared with those obtained from traditional survey methodologies (RTK-GPS and LiDAR). Present findings indicate that Pleiades stereo-imagery allows the acquisition of high resolution DEM with a RMS error that ranges from 0.35 to $0.48 \mathrm{~m}$. The largest errors were observed at the dune face, in regions with large shadow patches. Near-perfect agreement between Pleiades and concurrent methods (all computed CC were above 0.9 ) provides strong indications that this method can be used as a surveying tool to monitor detailed coastal morphological changes over large spatial domains.

Author Contributions: Conceptualization, L.P.A., R.A. and E.B.; data curation, L.P.A. and E.B.; methodology, E.B. and L.P.A.; validation, L.P.A.; writing-original draft preparation, L.P.A., B.A., E.W.J.B. and R.A.; writing-review and editing, all authors; field data acquisition, L.P.A., R.A., E.W.J.B., P.B., E.G. and O.A.D.; administration and funding acquisition, L.P.A. and R.A.

Funding: Luís Pedro Almeida was funded by a post-doctoral fellowship from the French Space Agency (CNES) to develop this work. Etienne Berthier acknowledges fundings from CNES through the TOSCA program. The work of Erwan Garel was supported by FCT research contract IF/00661/2014/CP1234. Paulo Baptista acknowledges the financial support to CESAM (UID/AMB/50017/2019), to FCT/MCTES through national funds, and the co-funding by the FEDER, within the PT2020 Partnership Agreement and Compete 2020.

Acknowledgments: The authors would like to thank the CNRS/LEGOS for funding the project the COMBI (2017) that allowed the development of the field campaign for the validation of the Pleiades products. We would like to thank the Mairie and Port de Capbreton for offering accommodation during the field campaign, and all the amazing support given during the experiment.

Conflicts of Interest: The authors declare no conflict of interest.

\section{References}

1. Hawker, L.; Bates, P.; Neal, J.; Rougier, J. Perspectives on Digital Elevation Model (DEM) Simulation for Flood Modeling in the Absence of a High-Accuracy Open Access Global DEM. Front. Earth Sci. 2018, 6, 233. [CrossRef]

2. Brasington, J.; Rumsby, B.T.; Mcvey, R.A. Monitoring and Modelling Morphological Changes in a Braided Gravel-Bed River Using HIgh Resolution GPS-Based Survey. Earth Surf. Process. Landf. 2000, 25, 973-990. [CrossRef]

3. Amante, C.J. Estimating Coastal Digital Elevation Model Uncertainty. J. Coast. Res. 2018, 34, $1382-1397$. [CrossRef]

4. Sallenger, A.H., Jr.; Krabill, W.B.; Swift, R.N.; Brock, J.; List, J.; Hansen, M.; Holman, R.A.; Manizade, S.; Sontag, J.; Meredith, A.; et al. Evaluation of airborne topographic lidar for quantifying beach changes. J. Coast. Res. 2003, 19, 125-133.

5. Nelson, A.; Reuter, H.I.; Gessler, P. DEM Production Methods and Sources. In Geomorphometry Concepts, Software, Applications; Hengl, T., Reuter, H.I., Eds.; Elsevier: Amsterdam, The Netherland, 2009; pp. 65-85.

6. Mancini, F.; Dubbini, M.; Gatteli, M.; Stecchi, F.; Fabbri, S.; Gabbianelli, G. Using Unmanned Aerial Vehicles (UAV) for High-Resolution Reconstruction of Topography: The Structure from Motion Approach on Coastal Environments. Remote Sens. 2013, 5, 6880-6898. [CrossRef]

7. Gonçalves, J.A.; Henriques, R. UAV photogrammetry for topographic monitoring of coastal areas. ISPRS J. Photogramm. Remote Sens. 2015, 104, 101-111. [CrossRef]

8. Turner, I.L.; Harley, M.D.; Drummond, C.D. UVA's for coastal surveying. Coast. Eng. 2016, 14, 19-24. [CrossRef]

9. Chen, B.; Yang, Y.; Wen, H.; Ruan, H.; Zhou, Z.; Luo, K.; Zhong, F. High-resolution monitoring of Beach topography and its change using unmanned aerial vehicle imagery. Ocean Coast. Manag. 2018, 160, 103-116. [CrossRef] 
10. Colomina, I.; Molina, P. Unmanned Aerial Systems for Photogrammetry and Remote Sensing: A Review. ISPRS J. Photogramm. Remote Sens. 2014, 92, 79-97. [CrossRef]

11. Niethammer, U.; James, M.; Rothmund, S.; Travelletti, J.; Joswig, M. UAV-based remote sensing of the Super-Sauze landslide: Evaluation and results. Eng. Geol. 2012, 128, 2-11. [CrossRef]

12. Gleyzes, J.P.; Meygret, A.; Fratter, C.; Panem, C.; Ballarin, S.; Valorge, C. SPOT5-System overview and image ground segment. In Proceedings of the IGARSS Conference, Toulouse, France, 21-25 July 2003.

13. Panagiotakis, E.; Chrysoulakis, N.; Charalampopoulou, V.; Poursanidis, D. Validation of Pleiades Tri-Stereo DSM in Urban Areas. Int. J. Geo-Inf. 2018, 7, 118. [CrossRef]

14. Marti, R.; Gascoin, S.; Berthier, E.; de Pinel, M.; Houet, T.; Laffly, D. Mapping snow depth in open alpine terrain from stereo satellite imagery. Cryosphere 2016, 10, 1361-1380. [CrossRef]

15. Zhou, Y.; Parsons, B.; Elliot, J.R.; Barisin, I.; Walker, R.T. Assessing the ability of Pleiades stereo imagery to determine height changes in earthquakes: A case study for the El Mayor-Cucapahepicentral area. J. Geophys. Res. Solid Earth 2015, 120, 8793-8808. [CrossRef]

16. Stumpf, A.; Malet, J.P.; Allemand, P.; Ulrich, P. Surface reconstruction and land-slide displacement measurements with Pleiades satellite images. ISPRS J. Photogramm. Remote Sens. 2014, 95, 1-12. [CrossRef]

17. Wagnon, P.; Vincent, C.; Arnaud, Y.; Berthier, E.; Vuillermoz, E.; Gruber, S.; Ménégoz, M.; Gilbert, A.; Dumont, M.; Shea, J.; et al. Seasonal and annual mass balances of Mera and Pokalde glaciers (Nepal Himalaya) since 2007. Cryosphere 2013, 7, 1769-1786. [CrossRef]

18. Berthier, E.; Vincent, C.; Magnusson, E.; Gunnlaugsson, A.; Pitte, P.; Le Meur, E.; Masiokas, M.; Ruiz, L.; Pálsson, F.; Belart, J.M.; et al. Glacier topography and elevation changes derived from Pleiades sub-meter stereo images. Cryosphere 2014, 8, 2275-2291. [CrossRef]

19. Abadie, S.; Butel, R.; Mauriet, S.; Morichon, D.; Dupuis, H. Wave climate and longshore drift on the South Aquitaine coast. Cont. Shelf Res. 2006, 26, 1924-1939. [CrossRef]

20. Pedreros, R.; Howa, H.; Michel, D. Application of grain size trens analysis for the determination of sediment transport pathways in intertidal areas. Mar. Geol. 1996, 135, 35-49. [CrossRef]

21. Castelle, B.; Guillot, B.; Marieu, V.; Chaumillon, E.; Hanquiez, V.; Bujan, S.; Poppeschi, C. Spatial and temporal patterns of shoreline change of a 280-km high-energy disrupted sandy coast from 1950 to 2014: SW France. Estuar. Coast. Shelf Sci. 2018, 200, 212-223. [CrossRef]

22. Castelle, B.; Bonneton, P.; Dupuis, H.; Sénéchal, N. Double bar beach dynamics on the high-energy meso-macrotidal French Aquitanian Coast: A review. Mar. Geol. 2007, 245, 141-159. [CrossRef]

23. Butel, R.; Dupuis, H.; Bonneton, P. Spatial Variability of Wave Conditions on the French Atlantic Coast using In-Situ Data. J. Coast. Res. 2002, 36, 96-108. [CrossRef]

24. Shean, D.E.; Alexandrov, O.; Moratto, Z.M.; Smith, B.E.; Joughin, I.R.; Porter, C.; Morin, P. An automated, open-source pipeline for mass production of digital elevation models (DEMs) from very-high-resolution commercial stereo satellite imagery. ISPRS J. Photogramm. Remote Sens. 2016, 116, 101-117. [CrossRef]

25. Bufton, J.L.; Garvin, J.B.; Cavanaugh, J.F.; Ramos-Izquierdo, L.; Clem, T.D.; Krabill, W.B. Airborne lidar for profiling of surface topography. Opt. Eng. 1991, 30, 72-78. [CrossRef]

26. Tsutsui, K.; Koya, K.; Kato, T. An investigation of continuous-angle laser light scattering. Rev. Sci. Instrum. 1998, 69, 3482-3486. [CrossRef]

27. Giles, P.T. Remote sensing and cast shadows in mountainous terrain. Photogramm. Eng. Remote Sens. 2001, 67, 833-839.

28. Ibarra-Delgado, S.; Cózar, J.R.; González-Linares, J.M.; Gómez-Luna, J.; Guil, N. Low-textured regions detection for improving stereoscopy algorithms. In Proceedings of the 2014 International Conference on High Performance Computing \& Simulation (HPCS), Bologna, Italy, 21-25 July 2014.

29. Duffy, J.P.; Shutler, J.D.; Witt, M.J.; De Bell, L.; Anderson, K. Tracking Fine-Scale Structural Changes in Coastal Dune Morphology Using Kite aerial Photography and Uncertainty-Assessed Structure-from-Motion Photogrammetry. Remote Sens. 2018, 10, 1494. [CrossRef]

30. Cook, K.L. An evaluation of the effectiveness of low-cost UAVs and structure from motion for geomorphic change detection. Geomorphology 2017, 278, 195-208. [CrossRef]

(C) 2019 by the authors. Licensee MDPI, Basel, Switzerland. This article is an open access article distributed under the terms and conditions of the Creative Commons Attribution (CC BY) license (http:/ / creativecommons.org/licenses/by/4.0/). 